\title{
Light Management: A Key Concept in High- Efficiency Perovskite/Silicon Tandem Photovoltaics
}

Light Management for the Future of Perovskite/Silicon Tandem Photovoltaics

Daniel A. Jacobs, ${ }^{a+}$ Malte Langenhorst,${ }^{b+}$ Florent Sahli, ${ }^{c}$ Bryce S. Richards, ${ }^{b, e}$ Thomas $P$.

White, ${ }^{a}$ Christophe Ballif, ${ }^{c, d}$ Kylie R. Catchpole, ${ }^{a} *$ Ulrich W. Paetzold ${ }^{b, e, *}$

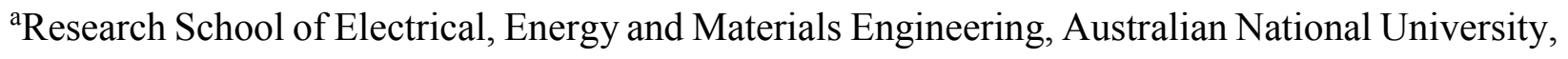
Canberra, Australia

${ }^{\mathrm{b}}$ Institute of Microstructure Technology, Karlsruhe Institute of Technology, Karlsruhe, Germany

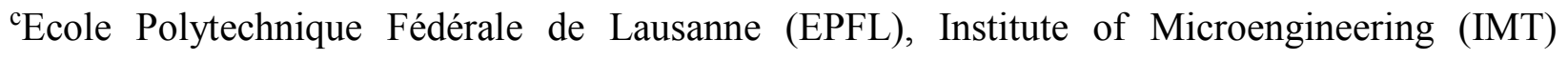

Photovoltaics and Thin-Film Electronics Laboratory (PV-Lab), Neuchâtel, Switzerland

${ }^{\mathrm{d} C S E M}$, PV-Center, Neuchâtel, Switzerland

e'Light Technology Institute, Karlsruhe Institute of Technology, Karlsruhe, Germany

\section{Corresponding Authors}

* ulrich.paetzold@kit.edu, kylie.catchpole@,anu.edu

+ these authors contributed equally 
The remarkable recent progress in perovskite photovoltaics affords a novel opportunity to advance the power conversion efficiency of market-dominating crystalline silicon (c-Si) solar cells. A severe limiting factor in the development of perovskite/c-Si tandems to date has been their inferior light-harvesting ability compared to single-junction c-Si solar cells, but recent innovations have made impressive headway on this front. Here, we provide a quantitative perspective on future steps to advance perovskite/c-Si tandem photovoltaics from a light-management point of view, addressing key challenges and available strategies relevant to both the 2-terminal and 4-terminal perovskite/c-Si tandem architectures. In particular, we discuss the challenge of achieving low optical reflection in 2-terminal cells, optical shortcomings in state-of-the-art devices, the impact of transparent electrode performance, and a variety of factors which influence the optimal bandgap for perovskite top-cells. Focused attention in each of these areas will be required to make the most of the tandem opportunity.

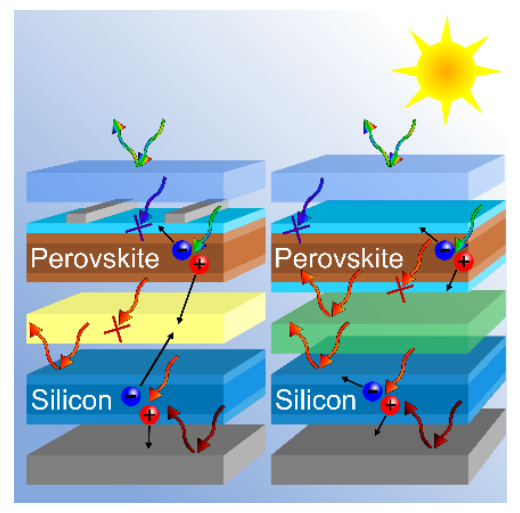

KEYWORDS Solar Cell, Photovoltaics, Optics, Perovskite, Silicon, Tandem, 4-terminal, 2terminal, Light-trapping 
Solar cells based on crystalline silicon (c-Si) have been enormously successful at driving the worldwide uptake of photovoltaics (PV), but are nearing their fundamental limit in terms of power conversion efficiency (PCE). As a result, there is limited scope to advance the PCE of commercially relevant PV with the kind of incremental approach that has brought the c-Si cell to its present position of market dominance. This puts an imminent constraint on further reductions in the cost/watt ratio of solar PV due to high area-related balance of system costs, which are especially large for residential installations. ${ }^{1}$ Metal halide perovskites have emerged as promising next-generation photovoltaic materials in recent years, but despite their remarkable performance and inherently low materials costs, these materials are unlikely to deliver single-junction PCEs significantly better than that of the incumbent c-Si technology. However, tandem cells in which a perovskite top cell absorbs the high-energy portion of the solar spectrum, with a c-Si bottom-cell in place to absorb much of the remainder, offer a route towards higher efficiency than either solar cell type could deliver in isolation. In consequence, perovskites represent a potentially low-cost and co-operative route for providing a step change boost to the PCE of commercially established c-Si cells. ${ }^{2}$

The detailed balance limit places the limiting PCE of tandem solar cells at around $46 \%$ compared to $33 \%$ for single-junctions. ${ }^{3}$ This results from the fact that high-energy photons absorbed in a wide bandgap semiconductor, such as the metal halide perovskites $\left(E_{\mathrm{G}} \sim 1.55-1.75 \mathrm{eV}\right)$, lose less energy to thermalization than they would in c-Si with its smaller bandgap of $1.1 \mathrm{eV}$. However, with the increased complexity of a tandem architecture it is also more challenging to close the gap between actual and theoretical performance. Imagining for a moment that the best single-junction perovskites cells could be applied with a "drop-in" approach to make tandems, there would still 
be a significant performance deficit in such devices due to optical losses induced by the tandem architecture. These losses stem from the large number of layers necessary to make functioning tandems (aside from the photoactive materials themselves), such as transparent electrodes, selective contacts, charge transport layers, passivation layers and coupling layers. The latter are specific to tandem architectures, which must include either a recombination junction (2-terminal, "2T") or an optical adhesive/spacer layer (4-terminal, "4T"), both of which put a drain on the tandem's current generation through their parasitic optical absorption. In addition, the large number of layers in a tandem stack gives rise to optical interfaces with strong contrasts in refractive index, inducing significant losses in the form of unwanted reflection. ${ }^{4}$

Encouragingly, within the last two years there have been several early demonstrations of perovskite/c-Si tandem devices with a PCE superior to that of their (high-performance) c-Si bottom-cells. ${ }^{5-12}$ Furthermore, the latest record PCE of a perovskite/c-Si tandem has reached a certified $28 \%,{ }^{12}$ thereby surpassing the best-in-class reported for single-junction c-Si $(26.7 \%){ }^{13}$ The next phase of development for perovskite/c-Si tandems will entail catching up to the performance of III-V/c-Si devices, which can currently achieve PCEs greater than $32 \%,{ }^{14,15}$ while retaining the chief advantage of perovskite materials in their low material cost and ease of fabrication. En route to this ambitious milestone, continued work on the optical optimization of perovskite/c-Si tandems will be necessary alongside processing and electrical improvements. Indeed, contrary to our supposition above, techniques for fabricating efficient perovskite singlejunctions cannot always be carried over straightforwardly to tandems. This is especially true for the $2 \mathrm{~T}$ architecture, in which the silicon bottom cell acts as the substrate for perovskite deposition, introducing distinct features such as a textured morphology and processing constraints that are absent for perovskite single-junctions. Consequently, electrical optimization will no doubt 
continue to play a major role in the development of viable perovskite/c-Si tandems. The key figure of merit illustrating the associated potential is the fill factor $(F F)$ of record-holding $2 \mathrm{~T}$ devices, which is presently in the range of $71-78 \%$ and therefore significantly below the $\sim 84 \%$ that should result from a combination of the best performing c-Si and perovskite cells. ${ }^{16,17}$ Many of the electrical and processing adjustments necessary to translate single-junction perovskites into the tandem architecture have been discussed extensively in the literature. ${ }^{18}$ However, several of the currently outstanding questions concerning perovskite/Si tandem development are largely related to optimal light management, and it is these questions that shall be our focus herein.

We begin this article with a brief review of the progress that has led to the present state of perovskite/c-Si tandem development from a light management point of view. Following recent developments in the field, a pressing question is whether texturing of the silicon bottom-cell in $2 \mathrm{~T}$ tandems is a necessary step to reduce reflection losses in these devices, given the complications that this introduces for the top-cell deposition. We will provide a perspective on this question based on recent modelling results, our own calculations, and a brief analysis of some available alternatives. Even more severe than the problem of reflection losses in most state-of-the-art devices is the issue of parasitic absorption, which we consider next with respect to state-of-the-art $2 \mathrm{~T}$ and 4T devices. Finally, we shall address that basic but crucial aspect of tandem light management which concerns the optimal distribution of light between a tandem's top and bottom cells. This question relates to the larger issues of perovskite bandgap tunability and to the competition between $2 \mathrm{~T}$ and $4 \mathrm{~T}$ architectures under realistic irradiation conditions, both of which shall be addressed in the context of energy yield modelling. 
We note that although the focus of this perspective is on analyzing developments and opportunities with respect to perovskite/c-Si tandems specifically, many of the same considerations will apply to related technologies, such as perovskite/CIGS, ${ }^{19,20} \mathrm{III}-\mathrm{V} / \mathrm{c}-\mathrm{Si},{ }^{14,21}$ and to an even greater degree in higher-order perovskite multi-junctions with $\mathrm{c}-\mathrm{Si}^{22}$ Throughout this article we consider both the $2 \mathrm{~T}$ and $4 \mathrm{~T}$ architectures, since each remains a commercially viable prospect at this time. The chief distinction is that in $4 \mathrm{~T}$ tandems the top- and bottom-cells are stacked mechanically and contacted individually (Fig. 1b), allowing each sub-cell to be operated at its maximum power point. By contrast, the sub-cells in a monolithic $2 \mathrm{~T}$ tandem are connected in series to make a single electrical device (Fig. 1a). At the module level, mechanically stacked tandems may also be wired together so as to require only a single inverter per string; however, we shall retain the designation of " $4 \mathrm{~T}$ " for these architectures since they are equivalent from an optical standpoint. ${ }^{23}$ The primary advantages and drawbacks of the $2 \mathrm{~T}$ and $4 \mathrm{~T}$ architectures have been discussed in detail elsewhere ${ }^{18,24,25}$ and will not be considered further here except in relation to Fig. 5 .

A History of Light Management in $2 T$ and $4 T$ Tandem Perovskite/c-Si Solar Cells. The PCE of perovskite/c-Si tandem devices has progressed hand-in-hand with advances in optical design. This is evident in Fig. 1, which depicts the evolution in external quantum efficiency (EQE) of both 2T (Fig. 1c) and 4T (Fig. 1d) tandems along with their PCE. Although EQE is a combined measure of both optical and electrical performance, the electrical component of EQE, the internal quantum efficiency (IQE), is expected to be high and spectrally flat for well-optimized perovskite and $\mathrm{Si}$ devices. At least one exception can be found in the literature describing a perovskite cell suffering from significant IQE losses in the blue part of the spectrum, ${ }^{26}$ although the PCE of that device was low (13.7\%) compared to all but the earliest cell results shown in Fig. 1. The remaining 
measurements, of which there are very few, indicate negligible IQE losses in perovskite cells with somewhat higher efficiencies. ${ }^{27-29}$ The IQE of commercially relevant silicon cells is also generally very high ( $>98 \%$ ) with minor variations for wavelengths $>1000 \mathrm{~nm}$ where the quality of the rearsurface passivation plays a role in collection efficiency. ${ }^{30}$ With these caveats in mind, the EQEs shown in Fig. 1 can be interpreted as being primarily an optical measure of light-harvesting ability. In Figs. 1(c,d) the EQE of a record c-Si single-junction solar cell (certified short-circuit current density of $43.3 \mathrm{~mA} \mathrm{~cm}{ }^{-2}$ with contact fingers) ${ }^{30}$ is also shown alongside the tandem data as a reference. This reference curve represents an aspirational target for tandem devices based on c-Si bottom-cells, since it is derived from a cell with electrical contacts on both sides (like tandems), and is approximately equal to unity over most of the spectrum except in the light-trapping regime beyond $1000 \mathrm{~nm}$.

One immediately apparent feature in the progression of Fig. 1 is that $2 \mathrm{~T}$ tandems have historically suffered from significant losses in the bluer half of the solar spectrum $(<550 \mathrm{~nm})$, whereas the $4 \mathrm{~T}$ tandems have conversely shown inferior current-gathering in the red-to-IR (i.e. below the perovskite bandgap $\approx 770 \mathrm{~nm}$ ). These trends in $\mathrm{EQE}$ reflect the distinct optical challenges inherent to each architecture as discussed in the following. Parasitic absorption in the blue and ultraviolet (UV) part of the solar spectrum $(<550 \mathrm{~nm})$ occurs largely in the front-side layers of a solar cell, particularly the front-side selective contact and transparent conductive oxide (TCO) layers. These layers must be of a very high optical quality to avoid strong parasitic absorption and retain high electrical conductivity at the same time. In $2 \mathrm{~T}$ tandems, the front-side layers come last in the fabrication sequence and consequently their quality is strongly compromised, both electrically and optically, due to several processing constraints. These constrains result from the need to avoid 
damaging the underlying perovskite layer, which requires the use of low-temperature deposition approaches, compatible solvents, and other concessions such as the inclusion of protective buffer layers. ${ }^{31,32}$ A prominent example of a poor compromise is the solution-processed Spiro-OMeTAD (2,2',7,7'-Tetrakis-(N,N-di-4-methoxyphenylamino)-9,9'-spirobifluorene), which was used as a hole transport layer (HTL) at the front side of the early $2 \mathrm{~T}$ tandems shown in Fig 1c. The parasitic absorption losses in the blue/UV region of the Spiro-OMeTAD HTL accounted for current density losses of up to $\sim 2.7 \mathrm{~mA} \mathrm{~cm}^{-2}{ }^{33}$ Improved blue responses were only very recently achieved in the $2 \mathrm{~T}$ architecture by evaporating alternative front-side charge transport layers, which allows very thin layers and thereby lower absorption. ${ }^{7,32}$ Nevertheless, considerable loss in these layers still remains an issue resulting in more than $1 \mathrm{~mA} \mathrm{~cm}^{-2}$ in harvestable current density being lost in the blue/UV part of the solar spectrum (see Fig. 3 and the ensuing discussion). ${ }^{32,7}$ By contrast, in the 4T tandem architecture the top and bottom solar cell are processed and contacted independently, allowing the optimal polarity of the devices architectures to be freely chosen and the front layers to be processed at high temperatures on a glass substrate. Typically, this has resulted in the frontside layers being processed at higher temperatures - for example TCOs, like indium tin oxide (ITO) or fluorine tin oxide (FTO) and electron transport layers (ETL) like mesoporous $\mathrm{TiO}_{2}$, compact $\mathrm{TiO}_{2}$ or compact $\mathrm{SnO}_{2}$ - all of which absorb very little light at wavelengths shorter than $380 \mathrm{~nm}$, accounting for the superior UV response of the $4 \mathrm{~T}$ tandem architecture compared to the 2T architecture (compare Figs. 1c,d) 
(a)

2T Architecture (Module)
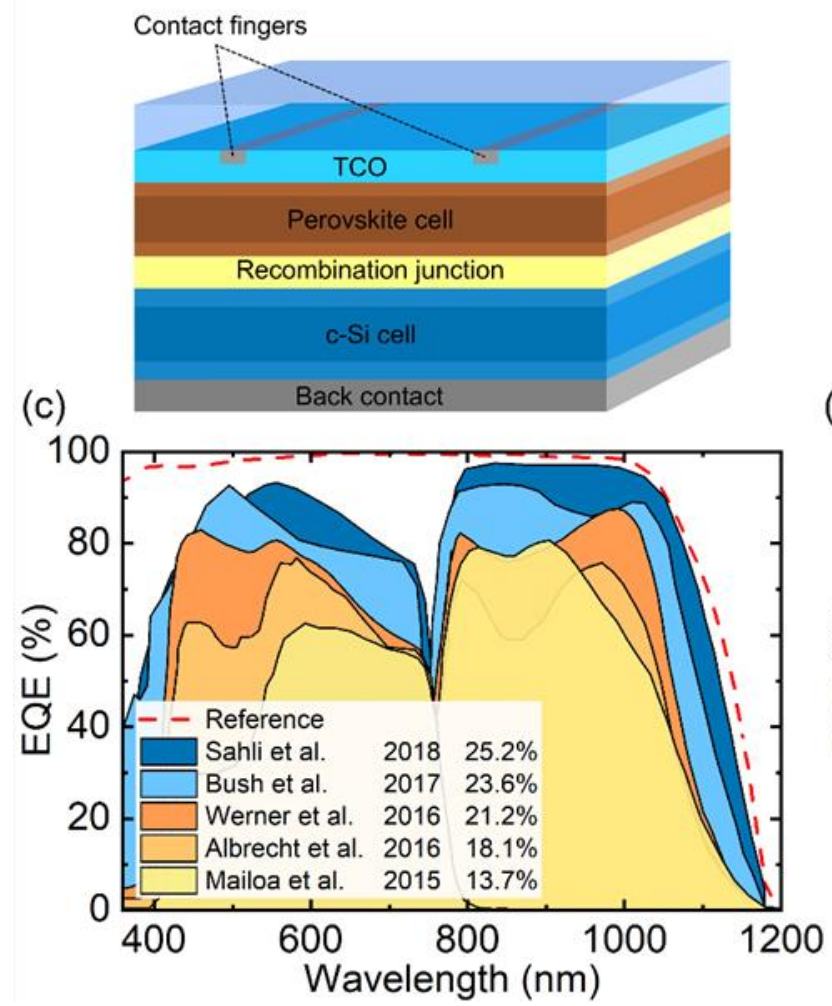

(b) 4T Architecture (Module)

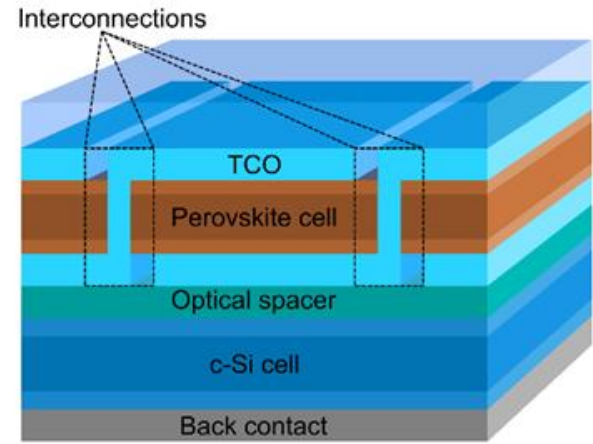

(d)

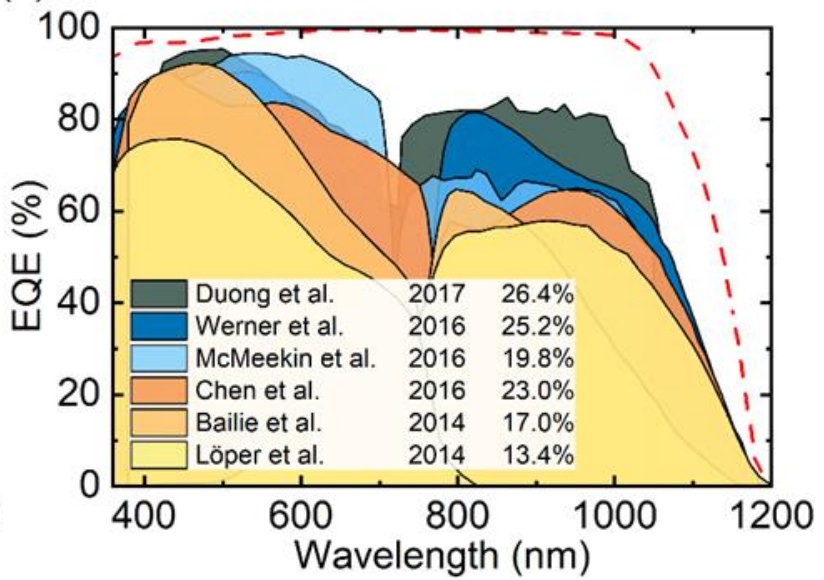

Fig. 1 Schematic of a perovskite/c-Si tandem solar module architecture in (a) 2T tandem architecture and (b) 4T tandem architecture. Historical evolution of the external quantum efficiency (EQE) of laboratory scale (c) 2T perovskite/c-Si tandem solar cells ${ }^{7,32,34-36}$ and (d) $4 \mathrm{~T}$ perovskite/c-Si tandem solar cells. ${ }^{6,19,36-39}$ Due to space limitations and for clarity some recent results are omitted. ${ }^{9-11}$ For comparison, we show the EQE of a single-junction c-Si solar cell with a short-circuit current density of $43.3 \mathrm{~mA}$ $\mathrm{cm}^{-2},{ }^{30}$ the highest certified short-circuit current density in a c-Si single-junction reported to date.

In theory, an excellent red/NIR response is attainable in perovskite/c-Si tandems due to the very low parasitic absorption of perovskite materials at energies below their bandgaps. ${ }^{40}$ However, the independent electrical operation of the perovskite top-cell and the c-Si bottom-cell in the 4T tandem architecture requires multiple transparent contacts, which, in turn, induce significant optical losses. On top of this, the optical coupling layers and adhesives used to bind the top- and bottom-cells also contribute to parasitic absorption in the NIR (see Fig. 3). The NIR-EQE for 4T tandems therefore remains capped at around $80 \%$ in the relevant spectral range $\left(E_{\mathrm{G}, \text { perovskite }}-\right.$ $\left.E_{\mathrm{G}, \mathrm{Si}}\right){ }^{6,9}$ with significantly poorer performance in the light-trapping regime compared to the c-Si reference. In this regard, $2 \mathrm{~T}$ tandems have the advantage of requiring only a single transparent electrode on their top side, and the use of coupling layers (recombination or tunnel junctions) with 
negligible optical absorption compared to the optical adhesives used to date in $4 \mathrm{~T}$ cells. These jointly result in much better EQE over 97\% in the NIR and excellent NIR light-trapping. ${ }^{7}$ Indeed, the NIR-EQE of the state-of-the-art $2 \mathrm{~T}$ tandem device shown in Fig. 1 is impressively close to that of the single junction c-Si reference already. We note that such high collection efficiency is also predicated on achieving ultra-low reflection, a challenge, which will be discussed further in the section on texturing. In conclusion, inferior NIR response represents an unavoidable drawback for 4T tandems, but opportunities beyond the current state-of-the-art exist in the optimization of TCO performance and in the use of thinner, less absorptive optical coupling layers. A detailed discussion concerning both of these aspects will be provided in the section on optical losses in state-of-theart devices (Fig. 3), and in a section addressing TCO performance in particular (Fig. 4).

To appreciate the size of the current densities in the remainder of this article, we suggest the approximate rule-of-thumb that $1 \mathrm{~mA} \mathrm{~cm}^{-2}$ in parasitic absorption (or reflection loss) for a $2 \mathrm{~T}$ tandem is worth $0.8 \%$ in absolute PCE. This assumes a well-optimized open-circuit voltage $\left(V_{\mathrm{OC}}\right)$ of $700 \mathrm{mV}$ (c-Si bottom-cell) $+1.2 \mathrm{~V}$ (perovskite top-cell) $=1.9 \mathrm{~V}$, a tandem FF of $0.83,{ }^{16,30}$ and that the optical loss in question is effectively broadband so that current matching is preserved. In general, the PCE loss will be underestimated by this rule for the case of imbalanced absorption occurring in a specific sub-cell, or for reflection that is not broadband. This approximate rule-ofthumb is therefore intended only as a ballpark estimate to put our optical calculations in perspective.

Texturing for reduced reflection. Whilst hardly significant in the current generation of record $4 \mathrm{~T}$ tandems, reflection losses can be a severe issue for $2 \mathrm{~T}$ tandems without dedicated light management strategies. In commercial single-junction c-Si cells the problem of high front-surface 
reflection is neatly resolved by anisotropic wet etching of the Si wafer's front surface, which results in random pyramids with a typical size of $\sim 1-5 \mu \mathrm{m}$. Rays reflected on first contact are typically collected on a second (the "double bounce" enhancement), reducing the solar-weighted reflection at normal incidence to only a few percent. At present the only processing route with a proven ability to conformally coat such large-scale textures, and therefore to fabricate $2 \mathrm{~T}$ tandems using commercially textured $\mathrm{c}-\mathrm{Si}$, is based on a hybrid evaporation/solution-process method of perovskite deposition. ${ }^{7}$ Looking forward, a large amount of research effort is currently being directed at realizing a fully co-evaporated sequence with a reduced number of process steps compared to the hybrid method as well as superior homogeneity. ${ }^{41}$ Such routes are attractive from an optical standpoint because the Si texture simultaneously addresses reflection from every one of a tandem's multiple interfaces, each being subject to the double-bounce enhancement, and also results in more efficient light trapping in the bottom-cell. However, the challenge of depositing a high-quality perovskite top-cell on a textured substrate naturally begs the question of viable alternatives. One possible alternative to employing fully textured wafers is to employ $\mathrm{Si}$ wafers with only a rear-side texture (and a polished surface for the perovskite top-cell), and to compensate by incorporating light-management textures on the tandem's front-side. ${ }^{8,36,42,43}$ Despite being optically inferior to a certain degree, these designs have achieved PCEs on par with the fullytextured design of ref. 7 due to their superior electrical characteristics, although this may be a transient advantage owing to the lesser-developed state of perovskite cell deposition on textured substrates. 

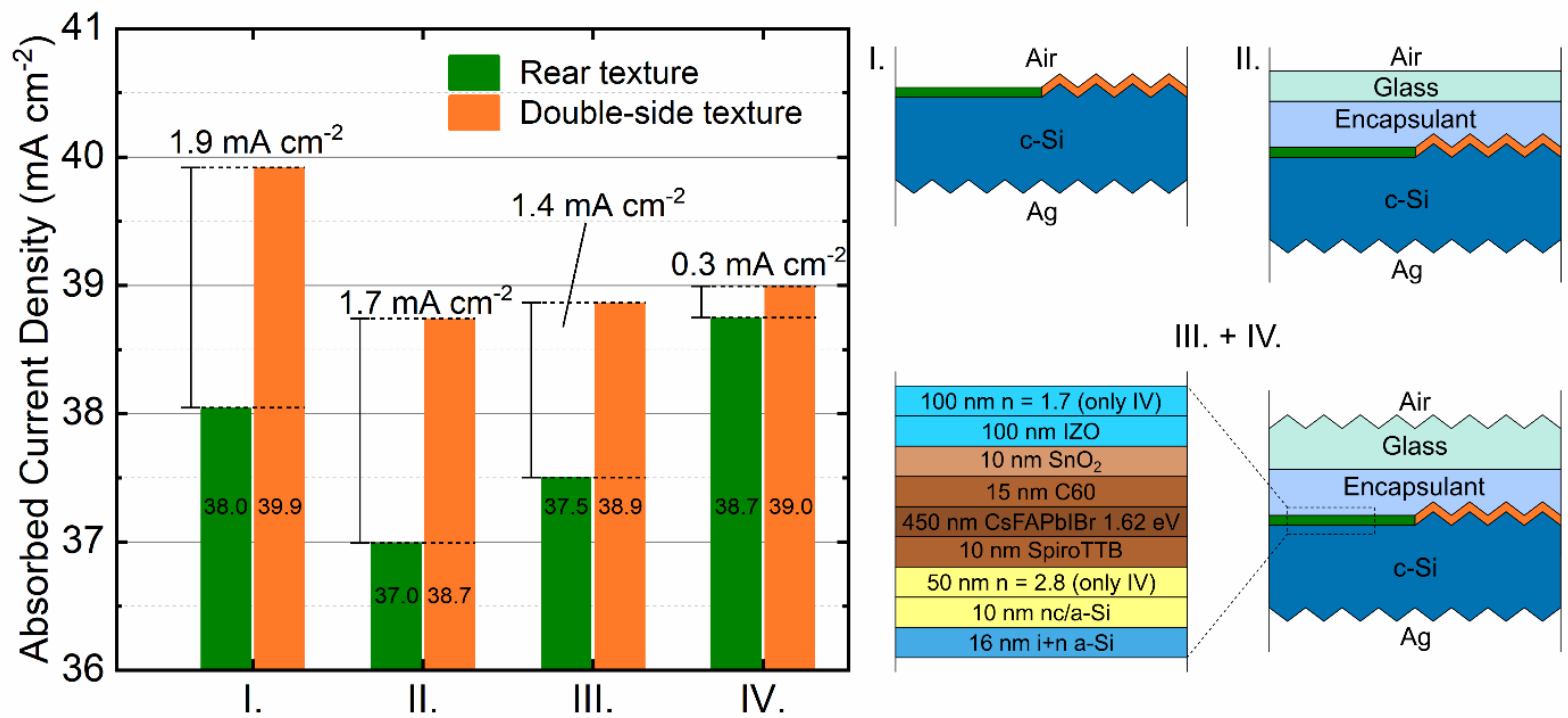

III. + IV.

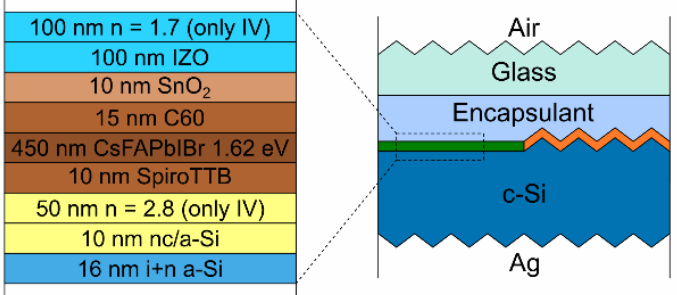

Fig. 2 Quantification of the optical impact of front-side texturing in $2 \mathrm{~T}$ tandems as a function of the cell environment. The discrepancy in total absorption (c-Si + perovskite absorption) between otherwise identical tandems with a rear-only texture and two-sided texture was calculated in four different settings: (I) emulating a lab-scale device without encapsulation, (II) cell in a module behind planar glass and EVA, (III) a module with a textured cover glass and (IV) a module with a textured cover glass and additional interlayers. In addition to the perovskite top-cell layer sequence shown, all structures incorporate an anti-reflection coating with $\mathrm{n} \sim 1.37$ (100nm $\mathrm{MgF}_{2}$ ) either directly on top of the cell (I) or on top of the glass encapsulation (II) - (IV).

To explore the competition between these alternatives at a purely optical level, Fig. 2 shows

calculations addressing the benefit of including a front-side texture in a $2 \mathrm{~T}$ tandem device. Results

are shown as a function of the cell's optical surrounding, whether it be air as in a lab-scale

measurement (structure I), or that of a module (structures II-IV). For the module results, we performed calculations using two designs employing either flat cover glass (II) or textured cover glass (III-IV) with an AR coating. Although textured cover glass is not yet common in the marketplace, several large-scale glass manufacturers offer rough-patterned glass products for PV modules at a similar price to that of conventional flat glass panels. ${ }^{44}$ Glass with deep textures should have optical properties similar to that of flat-panel glass with an LM foil, without the reliability concern introduced by polymeric materials that are prone to degrade over time in realistic outdoor conditions. ${ }^{45,46}$ The relative scarcity of textured glass in existing PV installations may be explained by the smaller benefit conferred by patterned glass to cells that are already textured, as are most single-junction Si cells. 
Shown in Fig. 2 is the total active-layer absorption (perovskite absorption+Si absorption) for each of the cases I-IV. It is apparent that the difference between a textured and flat c-Si surface is largest for structure I $\left(\sim 1.9 \mathrm{~mA} \mathrm{~cm}^{-2}\right)$, representing an unencapsulated lab-scale device in air. This figure is in good agreement with the calculations of Ref. ${ }^{47}$, which however employed a different top-cell stack. The transition from an air environment to encapsulation (EVA) in structure II reduces the benefit of cell texturing somewhat (from 1.9 to $1.7 \mathrm{~mA} \mathrm{~cm}^{-2}$ ). With textured glass on the module's front surface (structure III), the discrepancy between flat and textured cell surfaces reduces again to $\sim 1.4 \mathrm{~mA} \mathrm{~cm}{ }^{-2}$. Here the presence of an LM foil or glass texture plays a dual role of reducing reflection at the air-glass interface (benefiting both textured and un-textured cells equally) and of trapping some of the light reflected inside the module from the cell's front surface (relevant only to cells without a front-side texture). According to our rule-of-thumb above, such a $1.4 \mathrm{~mA} \mathrm{~cm}{ }^{-2}$ difference in active-layer absorption between the textured and flat-front $2 \mathrm{~T}$ tandems amounts to approximately $1.1 \%$ in absolute PCE, a figure which is neither completely game-changing nor entirely negligible. Provided that textured glass or LM foils are marketable, it therefore seems that both fully textured and front-side planar designs are viable from an optical standpoint, with the fully textured cells enjoying a significant, but not overwhelming advantage.

Several options exist for improving the optical performance of $2 \mathrm{~T}$ tandems with front-side polished Si beyond the $\sim 1.4 \mathrm{~mA} \mathrm{~cm}^{-2}$ absorption deficit calculated above, although each of these will entail additional cost in the form of processing complexity. In the top-cell stack used for the calculations of Fig. 2, the two most significant optical interfaces (sources of reflection) are the EVA/TCO interface and that between c-Si and hole-selective Spiro-TTB layer (or c-Si and the perovskite, since the hole-selective layer is optically almost negligible). The former can be addressed 
relatively easily with the inclusion of an $\mathrm{ARC}$ coating on top of the TCO, such as $\mathrm{SiO}_{0.4} \mathrm{~N}_{0.6}$ with its intermediate refractive index of $\sim 1.75$. Calculations suggest that this would add $\sim 0.5 \mathrm{~mA} \mathrm{~cm}{ }^{-2}$ to the absorption of flat-fronted tandems (data not shown). Reflection from the Si interface is harder to address without disrupting the cell structure. One option is to include an interlayer such as the index-tunable $\mathrm{SiO}_{\mathrm{x}}$ layer developed for micromorph tandems ${ }^{48}$ and taken up recently in calculations addressing the perovskite/c-Si system. ${ }^{49}$ According to these calculations, interlayers could improve tandem absorption by $\sim 0.3-0.5 \mathrm{~mA} \mathrm{~cm}^{-2}$, although we note that the effect of parasitic absorption in the interlayer was not considered in these estimates. Nano-texturing for reduced reflection can also be envisaged on both the perovskite's front-side, via the growth of textured perovskite capping layers ${ }^{50}$ or through imprint texturing, ${ }^{51}$ as well as at the c-Si interface via one of the many available texturing strategies. ${ }^{52-54}$ In the latter case, the depth of the required c-Si texture would not need to be as large as typical black-silicon designs due to the reduced index contrast (and significance of the reflections) at the perovskite/c-Si interface as compared with airSi. Our own calculations with graded-index layers in place of a nano-texture indicate that a depth of $\sim 150 \mathrm{~nm}$ may be sufficient to recover most of the $\sim 1 \mathrm{~mA} \mathrm{~cm}^{-2}$ in reflection contributed by the c-Si interface in planar $2 \mathrm{~T}$ tandems, a fairly modest depth which would be readily compatible with a solution-processed perovskite overlayer. ${ }^{51}$ However, it must be noted that approaches based on nano-texturing are likely to entail trade-offs with the electrical performance of both the top and bottom-cell, making it difficult to assess the real promise of such strategies at this stage. Nonetheless, to demonstrate the optical viability of these options we have included in structure IV of Fig. 2 a calculation with both an AR coating on the TCO and an interlayer at the Si interface, modifications which jointly increase absorption by $\sim 1.2 \mathrm{~mA} \mathrm{~cm}^{-2}$ in the planar tandem, reducing the discrepancy with respect to the fully textured cell to only $0.3 \mathrm{~mA} \mathrm{~cm}{ }^{-2}$. We note that this is 
considerably smaller than the $\sim 1 \mathrm{~mA} \mathrm{~cm}$ cm $^{-2}$ deficit in $\mathrm{J}_{\mathrm{sc}}$ (approx. $2 \mathrm{~mA} \mathrm{~cm}^{-2}$ in active-layer absorption) between single-side and double-side textured $2 \mathrm{~T}$ tandems calculated in ref 49 . Those calculations also included an interlayer, but compared tandems measured in air without the benefit of a textured glass cover or light-management foil.

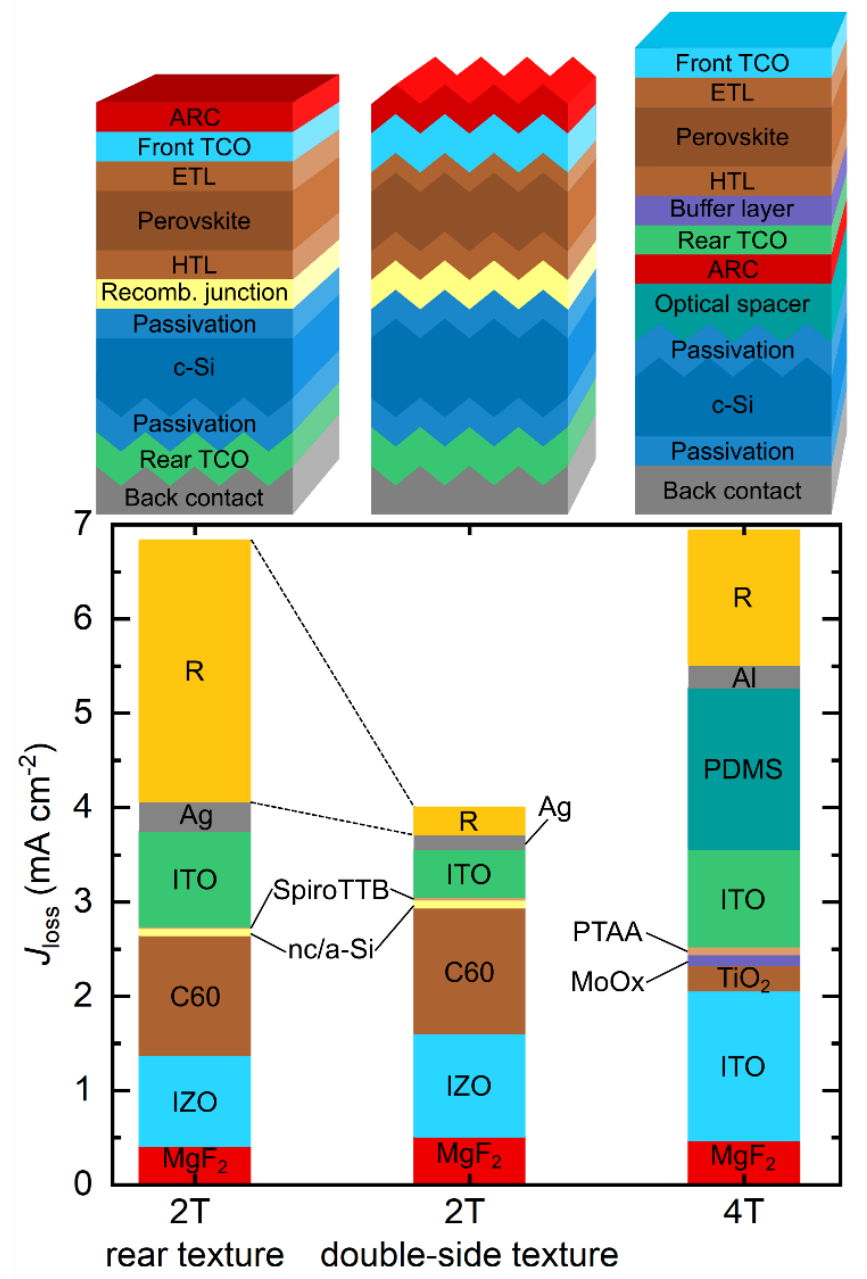

Fig. 3 Sources of optical loss in state-of-the art perovskite/c-Si tandem solar cells. Simulations were performed using an in-house model developed at KIT employing the transfer-matrix method for optically thin coherent layer stacks and a series expansion of Lambert-Beer's law for thick incoherent layers. Textures are taken into account by using geometrical ray tracing as proposed by Baker-Finch and McIntosh. ${ }^{55}$ For each device the model was calibrated with regard to the experimental EQE and (1-R) data of the investigated tandem solar cells. ${ }^{6,7}$ The front ARC (PDMS) and glass superstrate used in the $4 \mathrm{~T}$ tandem cell of ref. ${ }^{6}$ and in the corresponding simulations are omitted in the schematic.

The Problem of Parasitic Absorption. Despite the importance of maintaining low solar-weighted reflection, calculations frequently show that parasitic absorption is the larger optical loss channel 
in perovskite/c-Si tandems. These require a piecemeal approach to reduction as they are distributed between the many layers essential for fabricating high-efficiency tandem devices. We have performed our own quantitative analysis of the optical losses in state-of-the-art $2 \mathrm{~T}^{7}$ and $4 \mathrm{~T}^{6}$ tandem architectures to identify key bottlenecks, these are given in Fig. 3. The simulated $2 \mathrm{~T}$ tandem architecture in this figure is adapted from the first reported monolithically-integrated perovskite/cSi device incorporating a front-side (random pyramid) c-Si texture. ${ }^{7}$ For this cell we show simulations with and without the front-side random pyramids to quantify its effect on reflection (note that both cells were given a rear-side texture). Indeed, these calculations appear to confirm that parasitic absorption is the most significant loss channel in the current generation of state-ofthe-art perovskite/c-Si tandems. The unwanted absorption originates in several layers, with the most prominent being the TCOs, the antireflection coating ( $\mathrm{ARC}, \mathrm{MgF}_{2}$ in both architectures), the selective transport layers (ETL and HTL), the optical coupling layer (4T), and to a lesser extent the metal back contacts. The problem of parasitic absorption is therefore a multifaceted materials problem, but one which is notably easier to address with an evaporated top-cell sequence that allows for the deposition of ultra-thin conformal layers.

In the $2 \mathrm{~T}$ tandem architecture of Fig. 3, the worst offender in parasitic absorption is the front-side ETL of the perovskite top-cell (C60), although this already represents an improvement over many previous designs featuring Spiro-OMeTAD in the same position as mentioned previously. ${ }^{33,42}$ The current density loss of $\sim 1 \mathrm{~mA} \mathrm{~cm}^{-2}$ to parasitic absorption in $\mathrm{C} 60$ occurs in the blue part of the spectrum, despite the layer only being $15-20 \mathrm{~nm}$ thick. In theory, there is considerable scope for reducing the thickness of this layer, as $1 \mathrm{~nm}$ of $\mathrm{C} 60$ has been shown to be sufficient for the purpose of hole blocking, ${ }^{56}$ however the enhanced probability of pinhole formation - resulting in localized 
electrical shunt pathways - would need to be weighed in the balance. The other front-side layers - indium zinc oxide (IZO) and $\mathrm{MgF}_{2}$ - could also be further optimized in terms of thickness, or else replaced with better performing alternatives, e.g. swapping IZO with a superior TCO such as hydrogenated indium tungsten oxide (IWO:H), as discussed further below. Notably, almost no current is lost to parasitic absorption in the nc/a-Si:H recombination junction connecting the top and bottom cell ${ }^{57}$ - this represents a significant improvement over earlier designs incorporating ITO layers for the same purpose which contributed up to $1 \mathrm{~mA} \mathrm{~cm}^{-2}$ in current loss. ${ }^{33}$ Also worth mentioning in this context are the recently proposed 'interlayer-free' designs which omit the presence of additional recombination layers entirely. ${ }^{58,59}$

Regarding the present $4 \mathrm{~T}$ solar cell, absorption in the selective contacts is relatively negligible due to the favorable polarity of the solar cell architecture - annealed $\mathrm{TiO}_{2}$ on the sunward side, and poly[bis(4-phenyl)(2,4,6-trimethylphenyl)amine (PTAA) rear-facing. Nonetheless, a significant $\sim 1 \mathrm{~mA} \mathrm{~cm}^{-2}$ is lost in polydimethylsiloxane (PDMS) layer serving as an optical spacer layer between the top- and bottom- cell, mostly in the NIR, which can be attributed to molecular vibration of the polymer's $\mathrm{CH}_{3}$ group ${ }^{60}$ Here a reduction in the $\sim 1.5 \mathrm{~mm}$ PDMS thickness, far more than is used in conventional encapsulation and more than is necessary to bind the sub-cells, should be sufficient to recover most of the lost current.

Absorption in TCOs is by far the largest source of optical loss for 4T tandems, accounting for nearly $3 \mathrm{~mA} \mathrm{~cm}^{-2}$ in the state-of-the-art $4 \mathrm{~T}$ architecture (Fig. 3), and a sizeable amount ( $>1 \mathrm{~mA} \mathrm{~cm}^{-}$ ${ }^{2}$ ) in $2 \mathrm{~T}$ tandems. One way of reducing these losses would be to adopt superior TCO materials and deposition methods, as pointed out in a recent review. ${ }^{61}$ To illustrate the options available, Fig. 4 
shows the sheet resistance and average spectrally-weighted absorption of a wide range of TCOs that are potentially suited to deposition either on the front-side of a $2 \mathrm{~T}$ tandem, or on both the front- and rear-side of a $4 \mathrm{~T}$ top-cell, due to their compatibility with the low-temperature $\left(<150^{\circ} \mathrm{C}\right)$ processing that is required with a perovskite layer in place. According to this data, both sputtered IWO:H and hydrogenated indium oxide (IO:H) exhibit much lower solar-averaged absorption than any other TCO, coming in well ahead of ITO at similar sheet resistance. This indicates the potential for further developments in the field of TCOs, a relatively established domain of research, to impact emerging PV. Despite this relatively large spread in both sheet resistance and solaraveraged transparency, it is worth noting that such parameters are far from a straightforward indicator of performance in a photovoltaic module. Transparent electrode performance depends crucially on cell size and metallization parameters, a point where the $2 \mathrm{~T}$ and $4 \mathrm{~T}$ tandem architectures are importantly differentiated. Whereas $2 \mathrm{~T}$ perovskite/c-Si tandems are naturally the size of c-Si wafers (currently $239 \mathrm{~cm}^{2}$ ), and are likely to be contacted and metallized in much the same way, 4T tandem modules (see Fig. 1b) would be most straightforwardly constructed with the perovskite top-cells in an interconnected thin-film module structure, with narrow cell stripes (width $\approx 5 \mathrm{~mm}$ ) and no front-side metallization. ${ }^{8,62,63}$ As a result, the front-side transparent contact in a $4 \mathrm{~T}$ tandem module is likely to be a bare TCO, whereas in a $2 \mathrm{~T}$ tandem it will very likely be complemented by metallization in the form of fingers and bus-bars to carry current over the large lateral dimensions of a c-Si wafer. Similarly, the rear-side TCO of a 4T tandem top-cell can also be readily metallized. ${ }^{64}$ TCOs appearing in each location are therefore subject to different requirements and will have varying impacts on cell performance. As an illustration, in Fig. 4 we have calculated the effect of including optimized $50 \mu \mathrm{m}$-wide fingers on the effective sheet resistance and transparency of the grid $+\mathrm{TCO}$ combination, taking the bare TCO data ${ }^{61}$ as a starting 
point. The results make it clear that the inclusion of optimized metal fingers levels the competition between different TCOs quite considerably, since it allows for thinning of the most absorptive materials - for example FTO or IZO - with the reduction in sheet resistance compensated by the finger spacing. What appear to be large differences in TCO performance are therefore less relevant once metallization is taken into account. However, if a bare TCO must be used, as for example on the front-side of a 4T tandem, the differences between TCO materials and deposition methods can be highly significant (up to a dramatic $\sim 6 \%$ in parasitic absorption at a similar sheet resistance according to Fig. 4).

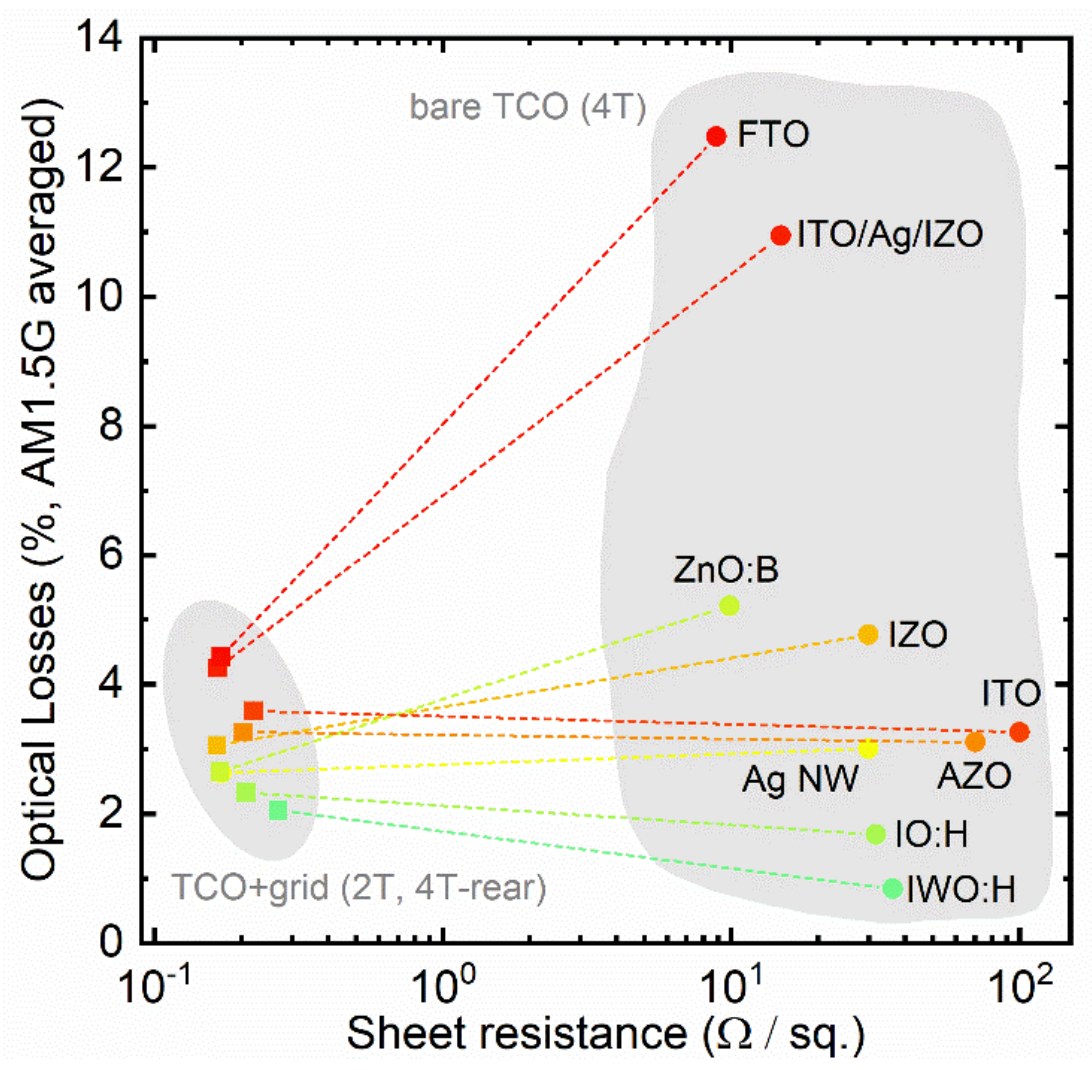

Fig. 4 Summarizing presentation of the variety in TCO performance that is achievable with different materials and deposition methods (primary data adapted from ref. ${ }^{61}$ ). Also shown is the effect of including metallization in the form of $50 \mu \mathrm{m} \times 10 \mu \mathrm{m}$ fingers (width $\mathrm{x}$ height) with optimized spacing on the resulting electrode's transparency and sheet resistance. The optical losses in this case account for both shading by the fingers and absorption in the TCO. For the grid calculation we assume that (1) each TCO can be reduced in thickness by a factor of up to $\sim 4$ from its original value (i.e. the value at which the TCO's transparency and sheet resistance was reported in ref. ${ }^{61}$ ) resulting in minimal final thicknesses of around $50 \mathrm{~nm}$, and that solar-weighted absorption scales proportionally, (2) that the grid is composed of fingers with a line-width of $\sim 50 \mu \mathrm{m}$, typical for contemporary industrial screen 
printing, and (3) the TCO thickness and finger spacing are optimized for conduction over a length of $2.5 \mathrm{~cm}$, corresponding to a 3 bus-bar configuration over a $156 \mathrm{~mm}$ wafer (bus-bar shading and ohmic loss are not included in the calculation).

Although not specific to tandem cells, another way of recovering lost current would be to invest in mitigating the optical impact of dead areas in perovskite/c-Si tandem solar modules due to bus bars, contact fingers, interconnection lines and the spacing between wafers. For 2T tandems, a reduction in dead-area loss is most likely to stem from the continued reduction in finger widths deposited via screen printing, now as small as $40 \mu \mathrm{m},{ }^{65}$ with techniques capable of $20 \mu \mathrm{m}$ on the horizon. ${ }^{66}$ Improved optical performance at the module level can also be foreseen in the form of new approaches to metallization, typified by the "SmartWire" technology of Meyer-Burger. ${ }^{67}$ Here, benefits accrue from the reduced thickness compared to standard bus bars (in much the same way as narrower fingers are advantageous) and from a reduced optical footprint due to a rounded cross-section. Even though the interconnects of the top-cell thin-film module structure in $4 \mathrm{~T}$ modules will be at least partly transparent to the bottom-cells, the large size of typical dead-area losses in thin-film modules $(5-10 \%)^{68,69}$ motivates the consideration of optical cloaking concepts. A variety of cloaking concepts have been suggested in the literature to reduce the effective deadarea of both tandem and single-junction modules. The proposed strategies encompass diffractive optics, ${ }^{70}$ reflective optics, ${ }^{71,72}$ refraction at "free-form surfaces", ${ }^{73,74}$ as well as recovering backscattered light via total internal reflection. ${ }^{75}$ However, it should be noted that these concepts are at a much lower level of technological readiness than the metallization schemes discussed above, and are mentioned here simply in the spirit of an outlook on possible directions for future research and development. 
Tandem Optics under Realistic Irradiation Conditions. In the previous sections we have addressed optical losses stemming from the auxiliary layers in the form of reflection and parasitic absorption; however, the most important optical layers are clearly the active layers themselves. In particular it is the optical absorption of the top-cell that largely determines the degree of current matching between top and bottom cells in a tandem, a quality which is crucial to achieving highperformance $2 \mathrm{~T}$ devices. Whereas losses in the auxiliary layers can be well-estimated by modelling layer-resolved absorption and reflection under standard testing conditions (STC: AM1.5G illumination under normal incidence and $25^{\circ} \mathrm{C}$ ) as done in the previous sections, the importance of top versus bottom cell absorption necessitates a more accurate approach to evaluate the relative performance of different designs and architectures. For this purpose, energy yield (EY) modelling becomes essential as it considers the many real-world variables which can affect the degree of current matching, such as geographically-variable levels of diffuse versus specular irradiation, and transient variations in both the spectrum and angle-of-incidence of solar radiation. ${ }^{25,76-78}$ Here we briefly discuss the relevance of these variations to the relative performance of the $2 \mathrm{~T}$ and $4 \mathrm{~T}$ architectures, and to the question of optimal perovskite bandgaps.

To illustrate the effect of realistic irradiation conditions on textured perovskite/c-Si tandem solar cells, we show simulated EY data for the two devices introduced earlier in the $4 \mathrm{~T}^{6}$ and $2 \mathrm{~T}^{7}$ configurations (Fig. 3). The EY figures were calculated for two representative locations with, on the one hand, a large share of specular irradiation (Phoenix, AZ) and, on the other hand, a large share of diffuse irradiation (Portland, OR). To ensure comparability between different bandgaps, we kept the $F F(\sim 78 \%)$ and $V_{\mathrm{OC}} / E_{\mathrm{G}}$ ratio $(\sim 75 \%)$ of each tandem constant. ${ }^{78}$ At each location, and under STC, we show the performance of these tandem devices "as is", that is with perovskite thicknesses and bandgaps as they were reported in the literature, alongside performance values 
calculated with the perovskite bandgaps and thickness optimized for maximal EY (here the perovskite thickness was limited to $750 \mathrm{~nm}$, considering typical state-of-the-art perovskite absorbers).

The EY modelling reveals several trends. To begin, a significant discrepancy is apparent between the bandgaps optimized under STC on the one side, and bandgaps computed for EY on the other. Assuming idealized, step-function absorption, the optimal top-cell bandgap for $2 \mathrm{~T}$ tandems is wellknown to reside in the region of $1.7-1.8 \mathrm{eV} \cdot{ }^{24,79}$ However, realistic optical imperfections related to parasitic and incomplete absorption induce corrections relative to these initial estimates. At both the cell and module level the majority of parasitic absorption in $2 \mathrm{~T}$ tandems occurs in the top-cell's region of absorption, which has the effect of lowering the optimal bandgap with respect to that of a step-function absorber under STC. Naturally, incomplete absorption in the perovskite top-cell due to its finite thickness will also lower the optimal bandgap. Indeed, the computations in Fig. 5 indicate an optimal bandgap of $1.66 \mathrm{eV}$ for both the $2 \mathrm{~T}$ and $4 \mathrm{~T}$ tandems under $\mathrm{STC}$, confirming this initial expectation. However, the optima computed on the basis of EY at both locations returns somewhat higher values 1.69-1.71 eV for both architectures (Fig. 5). The key reason for this discrepancy lies in the variation of spectral irradiance over the course of a year and in the average photon energy of local spectra. In sunny locations, the average photon energy tends to exceed that of AM1.5G, which has the effect of raising the optimal bandgap, contrary to the trends associated with sub-optimal top-cell absorption and front-side parasitic absorption. Although locations with a significant fraction of diffuse radiation tend to see a reduction in the average photon energy, an overall a trend to higher optimal bandgaps still predominates compared to STC. ${ }^{76}$

A second result of our EY modelling concerns the relative performance of the $2 \mathrm{~T}$ and $4 \mathrm{~T}$ architectures under realistic irradiation conditions. The requirement of current-matching in $2 \mathrm{~T}$ 
tandems raises obvious questions concerning the performance of these cells in terrestrial environments that entail significant temporal variation in the solar spectrum. Comparing again the two state-of-the-art representatives, EY modelling confirms the higher sensitivity of the $2 \mathrm{~T}$ architecture to realistic irradiation conditions, at least when the cells are simulated "as is", i.e. with the bandgaps and perovskite thicknesses they were reported with in the literature, not optimized for the conditions under which they are simulated. In terms of nominal power under STC, the unmodified $4 \mathrm{~T}$ architecture outperforms the unmodified $2 \mathrm{~T}$ architecture by $4.6 \%$ relative (Fig. 5), a discrepancy which increases up to a $\sim 10 \%$ difference in EY when the same cells are subjected to realistic irradiation conditions (Phoenix and Portland). However, the discrepancy between $2 \mathrm{~T}$ and $4 \mathrm{~T}$ performance largely vanishes when the perovskite bandgap and thickness are optimized at each location (or for STC). Once optimized, the textured $2 \mathrm{~T}$ tandem has a slight advantage of $1.4 \%$ in relative nominal power under AM1.5G conditions. This slight advantage is diminished for realistic time-of-day and seasonal spectral variations at both Phoenix and Portland. Nevertheless, the effect of transient current-mismatch is not too large and it is significant that the $2 \mathrm{~T}$ architecture, once optimized carefully, yields similar performance to the $4 \mathrm{~T}$ architecture under realistic irradiation conditions.

Although the halide perovskites enjoy a large degree of bandgap tunability, much of their compositional space is hampered by poor operational stability. In particular, many of the highbandgap compositions incorporating large fractions of $\mathrm{Br}$ are prone to phase segregate under illumination and forward bias. Long-term stability under operating conditions is therefore likely to play a larger role in the selection of appropriate top-cell compositions than the optimal bandgaps for tandem performance. The results of Fig. 5 indicate that $2 \mathrm{~T}$ performance will be very close to that of the $4 \mathrm{~T}$ architecture if a stable high-bandgap composition can be found, and furthermore that 
little to no location-specific optimization will be required to achieve good current-matching. If on the other hand the stable composition manifests a lower bandgap, the thickness of the $2 \mathrm{~T}$ top-cell will need to be adjusted significantly to match local spectra, and tandem performance will be lower compared to that of the $4 \mathrm{~T}$ architecture ${ }^{80}$ From this perspective, the competition between $2 \mathrm{~T}$ and 4T tandems will be decided to a large degree by the extent to which long-term stability constrains the availability of different top-cell bandgaps.

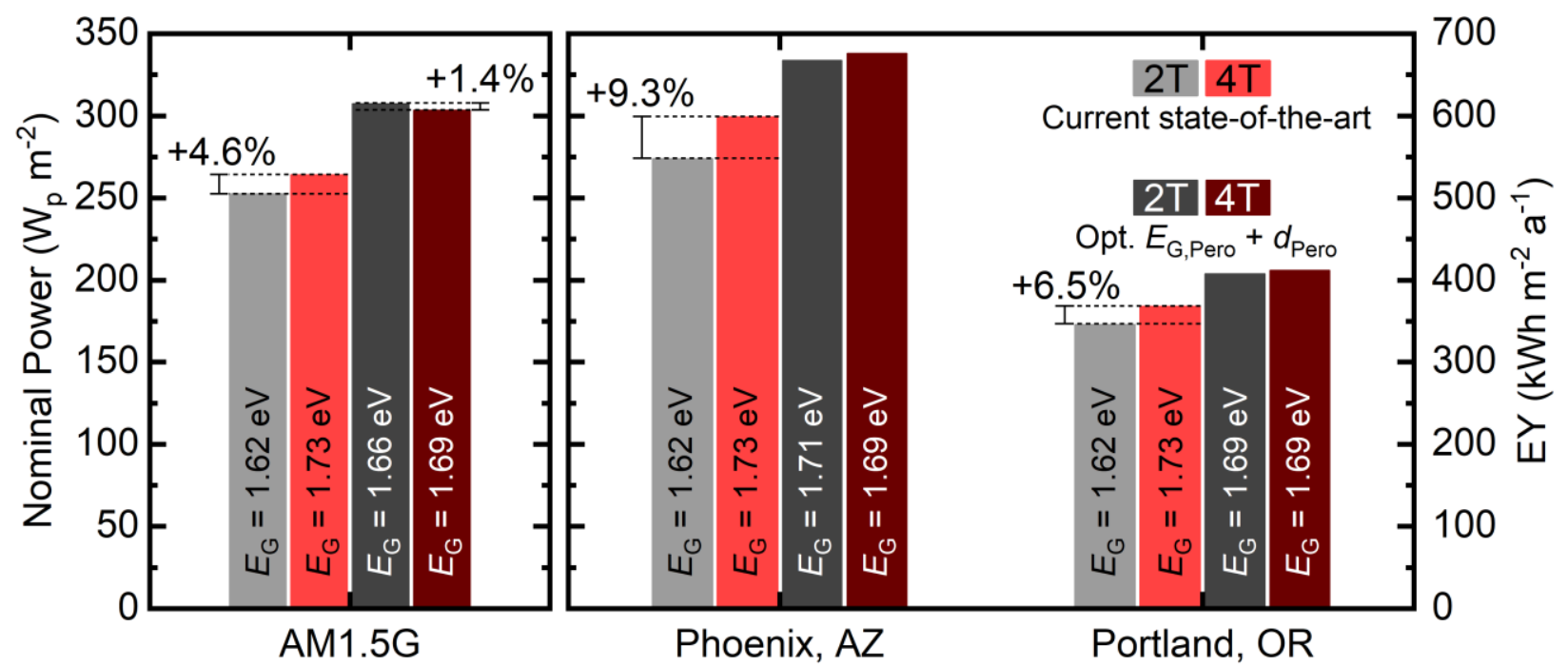

Fig. 5 Comparison between nominal power output under STC (left), and realistic energy yield (right) of the 2 -terminal (2T) ${ }^{7}$ and 4-terminal $(4 \mathrm{~T})^{6}$ perovskite/c-Si tandem devices considered throughout this paper. Energy yield was calculated with an optimized tilt angle in two locations with a large share of specular irradiation (Phoenix, AZ) and of diffuse irradiation (Portland, OR). Data is shown for the tandem devices as reported in the literature (grey and red bars) and with optimized perovskite bandgaps (indicated) and thicknesses (black and brown). For the latter a maximum allowable thickness of 750nm was assumed. Labels indicate relative differences in nominal power (equivalently PCE) and EY.

Conclusion. In summary, this perspective highlights the importance of light management for the advancement of perovskite/c-Si tandem photovoltaics. Whilst several recent publications have rightly emphasized the development of new perovskite materials, interfaces and device architectures, progress in this area has hinged equally on improved device architectures that reduce optical losses due to reflection and parasitic absorption. Moreover, there is still significant potential remaining to improve the optical design of perovskite/c-Si tandem cells. 
One of the most important questions in this area concerns the optical significance of employing fully textured Si cells in $2 \mathrm{~T}$ tandems, given what this entails for the perovskite top-cell deposition. Since a fully solution-processed sequence is apparently ruled out by the large feature sizes of typical Si textures, the question marks a fork in the road for the community working on $2 \mathrm{~T}$ tandem development. Fully textured tandems enjoy a significant but not overwhelming advantage over tandems fabricated on selectively (single-side) textured wafers, to the tune of $\sim 1.1 \%$ in PCE for cells in a module environment behind textured glass, or with a light-management foil in place. However, with the inclusion of an additional anti-reflection coating, and an interlayer or nanotexture at the Si interface, we found that such planar-top-cell designs can achieve essentially equivalent optical performance to their fully textured counterparts. Despite this, the number of processing steps involved in the latter optimization may not justify the additional cost. Notably, from an industrial standpoint it is simpler to produce doubly-textured Si wafers than single-side textured wafers, suggesting that designs employing the latter will have to make up for the additional processing complexity at other stages in the fabrication sequence. Alternatively, it may transpire that planar top-cells will enjoy a significant advantage in electrical characteristics - the likelihood of this is difficult to assess at the present moment given the relatively underdeveloped state of methods for depositing perovskites on textured substrates, which makes a fair comparison to planar solution-processed top-cells impossible.

We have seen that in the 4T architecture TCO absorption and avoidable losses in the optical adhesive are largely to blame for sub-optimal NIR EQE in the current record-holding tandem device. TCO absorption can be ameliorated by taking advantage of high-performing alternatives 
to the standard ITO such as IWO:H and IO:H, as well as by judiciously matching the TCO's region of absorption, whether primarily in the UV or NIR, to its location in the tandem stack. Developments are also ongoing in the field of scalable techniques for printing narrow-width metal lines, and of optically cloaking the dead area losses; such efforts have the potential to even further improve optical performance of both $2 \mathrm{~T}$ and $4 \mathrm{~T}$ devices on the timescale over which tandems are likely to be commercialized. For $2 \mathrm{~T}$ devices with a front-side texture, the primary challenge, apart from retaining good electrical performance, will be maintaining low parasitic absorption in the front-side TCO and selective contacts. For the latter, materials development in the area of suitable wide-bandgap semiconductors with low absorption, or the ability to function at optically negligible thicknesses, seems to be the only way forward.

An important aspect of perovskite/c-Si tandem development concerns the competition between textured $2 \mathrm{~T}$ and $4 \mathrm{~T}$ architectures under realistic irradiation conditions. Regarding the real world application of PV modules, EY modelling shows that the $4 \mathrm{~T}$ architecture is more tolerant in terms of annual EY towards realistic irradiation conditions, requiring less location-specific optimization. Nevertheless, the $2 \mathrm{~T}$ architecture can attain an EY closely comparable to that of $4 \mathrm{~T}$ tandems provided that the top-cell thickness and bandgap are optimized to match local conditions. If the top-cell bandgap is not barred from reaching high values $\sim 1.7 \mathrm{eV}$, only minimal location-specific optimization would be required to obtain equivalent performance. However, more significant location-specific changes are required to achieve current-matching with lower bandgaps, which could impact the commercial viability of the $2 \mathrm{~T}$ architecture if stability constraints favor lowerbandgap compositions. These considerations highlight the point that variations in local spectral 
irradiance need to be considered in the identification of a superior tandem architecture for commercialization.

Overall, there is significant room to improve the optical performance of both $2 \mathrm{~T}$ and $4 \mathrm{~T}$ perovskite/c-Si tandems, comparable to the remaining scope for electrical optimization. Future research and development will have to carefully navigate the balance between electrical and optical aspects, on top of considerations of process complexity, in order to harvest the full cost-advantage of the perovskite/c-Si Tandem PV opportunity. 


\section{ACKNOWLEDGEMENTS}

This work has been partly supported by the Australian Government through the Australian Renewable Energy Agency (ARENA). Responsibility for the views, information or advice expressed herein is not accepted by the Australian Government. KRC acknowledges the support of a Future Fellowship from the Australian Research Council. M.L., B. S. R. and U. W. P. acknowledge financial support of the Bundesministerium für Bildung und Forschung (PRINTPERO, PEROSOL), the Initiating and Networking funding of the Helmholtz Association (HYIG of Dr. U.W. Paetzold; Recruitment Initiative of Prof. B.S. Richards; the Helmholtz Energy Materials Foundry (HEMF); PEROSEED); the European Union's Horizon2020 program (ACTPHAST); and the Science and Technology of Nanostructures research program) as well as

the Karlsruhe School of Optics \& Photonics (KSOP). F. S. and C. B acknowledge the financial support of the Swiss National Science Foundation via NRP70 Energy Turnaround PV2050 and Swiss National Science Foundation Bridge (176552) projects.

\section{REFERENCES}

(1) Sofia, S. E.; Mailoa, J. P.; Weiss, D. N.; Stanbery, B. J.; Buonassisi, T.; Peters, I. M. Economic Viability of Thin-Film Tandem Solar Modules in the United States. Nat. Energy 2018, 3, 387-394 DOI:10.1038/s41560-018-0126-z.

(2) Green, M. A. Commercial Progress and Challenges for Photovoltaics. Nat. Energy 2016, 1, 15015 DOI:10.1038/nenergy.2015.15.

(3) Vos, A. De. Detailed Balance Limit of the Efficiency of Tandem Solar Cells. J. Phys. D. Appl. Phys. 1980, 13, 839-846 DOI:10.1088/0022-3727/13/5/018.

(4) Grant, D. T.; Catchpole, K. R.; Weber, K. J.; White, T. P. Design Guidelines for Perovskite/Silicon 2-Terminal Tandem Solar Cells: An Optical Study. Opt. Express 2016, 24, A1454 DOI:10.1364/OE.24.0A1454.

(5) OxfordPV. Oxford PV sets world record for perovskite solar cell https:/www.oxfordpv.com/news/oxford-pv-sets-world-record-perovskite-solar-cell 
(accessed Nov 30, 2018).

(6) Duong, T.; Wu, Y.; Shen, H.; Peng, J.; Fu, X.; Jacobs, D.; Wang, E.-C.; Kho, T. C.; Fong, K. C.; Stocks, M.; et al. Rubidium Multication Perovskite with Optimized Bandgap for Perovskite-Silicon Tandem with over 26\% Efficiency. Adv. Energy Mater. 2017, 7 , 1700228 DOI:10.1002/aenm.201700228.

(7) Sahli, F.; Werner, J.; Kamino, B. A.; Bräuninger, M.; Monnard, R.; Paviet-Salomon, B.; Barraud, L.; Ding, L.; Diaz Leon, J. J.; Sacchetto, D.; et al. Fully Textured Monolithic Perovskite/Silicon Tandem Solar Cells with 25.2\% Power Conversion Efficiency. Nat. Mater. 2018, 17, 820-826 DOI:10.1038/s41563-018-0115-4.

(8) Jaysankar, M.; Filipič, M.; Zielinski, B.; Schmager, R.; Song, W.; Qiu, W.; Paetzold, U. W.; Aernouts, T.; Debucquoy, M.; Gehlhaar, R.; et al. Perovskite-silicon Tandem Solar Modules with Optimised Light Harvesting. Energy Environ. Sci. 2018, 11, 1489-1498 DOI:10.1039/C8EE00237A.

(9) Ramírez Quiroz, C. O.; Shen, Y.; Salvador, M.; Forberich, K.; Schrenker, N.; Spyropoulos, G. D.; Heumüller, T.; Wilkinson, B.; Kirchartz, T.; Spiecker, E.; et al. Balancing Electrical and Optical Losses for Efficient 4-Terminal Si-perovskite Solar Cells with Solution Processed Percolation Electrodes. J. Mater. Chem. A 2018, 6, 3583-3592 DOI:10.1039/C7TA10945H.

(10) Chen, B.; Yu, Z.; Liu, K.; Zheng, X.; Liu, Y.; Shi, J.; Spronk, D.; Rudd, P. N.; Holman, Z.; Huang, J. Grain Engineering for Perovskite/Silicon Monolithic Tandem Solar Cells with Efficiency of 25.4\%. Joule 2019, 3, 177-190 DOI:10.1016/j.joule.2018.10.003.

(11) Jošt, M.; Köhnen, E.; Morales-Vilches, A. B.; Lipovšek, B.; Jäger, K.; Macco, B.; AlAshouri, A.; Krč, J.; Korte, L.; Rech, B.; et al. Textured Interfaces in Monolithic Perovskite/Silicon Tandem Solar Cells: Advanced Light Management for Improved Efficiency and Energy Yield. Energy Environ. Sci. 2018, 11, 3511-3523 DOI:10.1039/C8EE02469C.

(12) Oxford PV perovskite solar cell achieves $28 \%$ efficiency https://www.oxfordpv.com/news/oxford-pv-perovskite-solar-cell-achieves-28-efficiency (accessed Mar 8, 2019).

(13) NREL. Best Research-Cell Efficiencies https:/www.nrel.gov/pv/assets/pdfs/pvefficiencies-07-17-2018.pdf (accessed Nov 30, 2018).

(14) Essig, S.; Allebé, C.; Remo, T.; Geisz, J. F.; Steiner, M. A.; Horowitz, K.; Barraud, L.; Ward, J. S.; Schnabel, M.; Descoeudres, A.; et al. Raising the One-Sun Conversion Efficiency of III-V/Si Solar Cells to $32.8 \%$ for Two Junctions and $35.9 \%$ for Three Junctions. Nat. Energy 2017, 2, 17144 DOI:10.1038/nenergy.2017.144.

(15) Cariou, R.; Benick, J.; Feldmann, F.; Höhn, O.; Hauser, H.; Beutel, P.; Razek, N.; Wimplinger, M.; Bläsi, B.; Lackner, D.; et al. III-V-on-Silicon Solar Cells Reaching 33\% Photoconversion Efficiency in Two-Terminal Configuration. Nat. Energy 2018, 3, 326-333 DOI:10.1038/s41560-018-0125-0.

(16) Stolterfoht, M.; Wolff, C. M.; Amir, Y.; Paulke, A.; Perdigón-Toro, L.; Caprioglio, P.; Neher, D. Approaching the Fill Factor Shockley-Queisser Limit in Stable, Dopant-Free 
Triple Cation Perovskite Solar Cells. Energy Environ. Sci. 2017, 10, 1530-1539 DOI:10.1039/C7EE00899F.

(17) Battaglia, C.; Cuevas, A.; De Wolf, S. High-Efficiency Crystalline Silicon Solar Cells: Status and Perspectives. Energy Environ. Sci. 2016, 9, 1552-1576.

(18) Werner, J.; Niesen, B.; Ballif, C. Perovskite/Silicon Tandem Solar Cells: Marriage of Convenience or True Love Story? - An Overview. Adv. Mater. Interfaces 2018, 5, 1700731 DOI:10.1002/admi.201700731.

(19) Bailie, C. D.; Christoforo, M. G.; Mailoa, J. P.; Bowring, A. R.; Unger, E. L.; Nguyen, W. H.; Burschka, J.; Pellet, N.; Lee, J. Z.; Grätzel, M.; et al. Semi-Transparent Perovskite Solar Cells for Tandems with Silicon and CIGS. Energy Environ. Sci. 2015, 8, 956-963 DOI:10.1039/C4EE03322A.

(20) Han, Q.; Hsieh, Y.-T.; Meng, L.; Wu, J.-L.; Sun, P.; Yao, E.-P.; Chang, S.-Y.; Bae, S.-H.; Kato, T.; Bermudez, V.; et al. High-Performance Perovskite/Cu(In,Ga)Se 2 Monolithic Tandem Solar Cells. Science (80-. ). 2018, 361, 904-908 DOI:10.1126/science.aat5055.

(21) Cariou, R.; Benick, J.; Feldmann, F.; Höhn, O.; Hauser, H.; Beutel, P.; Razek, N.; Wimplinger, M.; Bläsi, B.; Lackner, D.; et al. Author Correction: III-V-on-Silicon Solar Cells Reaching 33\% Photoconversion Efficiency in Two-Terminal Configuration. Nat. Energy 2018, 3, 606-606 DOI:10.1038/s41560-018-0208-y.

(22) Werner, J.; Sahli, F.; Fu, F.; Diaz Leon, J. J.; Walter, A.; Kamino, B. A.; Niesen, B.; Nicolay, S.; Jeangros, Q.; Ballif, C. Perovskite/Perovskite/Silicon Monolithic TripleJunction Solar Cells with a Fully Textured Design. ACS Energy Lett. 2018, 3, 2052-2058 DOI:10.1021/acsenergylett.8b01165.

(23) M. Stocks, Y.X. Loo, N. N. L. Free the Bandgap! Series-Parallel Connection of Tandem Cells. In 32nd European Photovoltaic Solar Energy Conference and Exhibition; 2017; pp 223-227 DOI:10.4229/EUPVSEC20162016-1BV.6.12.

(24) Futscher, M. H.; Ehrler, B. Efficiency Limit of Perovskite/Si Tandem Solar Cells. ACS Energy Lett. 2016, 1, 863-868.

(25) Dupré, O.; Niesen, B.; De Wolf, S.; Ballif, C. Field Performance versus Standard Test Condition Efficiency of Tandem Solar Cells and the Singular Case of Perovskites/Silicon Devices. J. Phys. Chem. Lett. 2018, 9, 446-458.

(26) Ball, J. M.; Stranks, S. D.; Hörantner, M. T.; Hüttner, S.; Zhang, W.; Crossland, E. J. W.; Ramirez, I.; Riede, M.; Johnston, M. B.; Friend, R. H.; et al. Optical Properties and Limiting Photocurrent of Thin-Film Perovskite Solar Cells. Energy Environ. Sci. 2015 DOI:10.1039/c4ee03224a.

(27) Yang, B.; Dyck, O.; Poplawsky, J.; Keum, J.; Puretzky, A.; Das, S.; Ivanov, I.; Rouleau, C.; Duscher, G.; Geohegan, D. Perovskite Solar Cells with near 100\% Internal Quantum Efficiency Based on Large Single Crystalline Grains and Vertical Bulk Heterojunctions. $J$. Am. Chem. Soc. 2015, 137, 9210-9213.

(28) Lin, Q.; Armin, A.; Nagiri, R. C. R.; Burn, P. L.; Meredith, P. Electro-Optics of Perovskite Solar Cells. Nat. Photonics 2015, 9, 106-112 DOI:10.1038/nphoton.2014.284. 
(29) Burschka, J.; Pellet, N.; Moon, S.-J. J.; Humphry-Baker, R.; Gao, P.; Nazeeruddin, M. K.; Grätzel, M.; Gratzel, M. Sequential Deposition as a Route to High-Performance PerovskiteSensitized Solar Cells. Nature 2013, 499, 3-7 DOI:10.1038/nature12340.

(30) Richter, A.; Benick, J.; Feldmann, F.; Fell, A.; Hermle, M.; Glunz, S. W. N-Type Si Solar Cells with Passivating Electron Contact: Identifying Sources for Efficiency Limitations by Wafer Thickness and Resistivity Variation. Sol. Energy Mater. Sol. Cells 2017, 173, 96105 DOI:10.1016/j.solmat.2017.05.042.

(31) Werner, J.; Dubuis, G.; Walter, A.; Löper, P.; Moon, S.-J.; Nicolay, S.; Morales-Masis, M.; De Wolf, S.; Niesen, B.; Ballif, C. Sputtered Rear Electrode with Broadband Transparency for Perovskite Solar Cells. Sol. Energy Mater. Sol. Cells 2015, 141, 407-413 DOI:10.1016/j.solmat.2015.06.024.

(32) Bush, K. A.; Palmstrom, A. F.; Yu, Z. J.; Boccard, M.; Cheacharoen, R.; Mailoa, J. P.; McMeekin, D. P.; Hoye, R. L. Z.; Bailie, C. D.; Leijtens, T.; et al. 23.6\%-Efficient Monolithic Perovskite/Silicon Tandem Solar Cells with Improved Stability. Nat. Energy 2017, 2, 17009 DOI:10.1038/nenergy.2017.9.

(33) Wu, Y.; Yan, D.; Peng, J.; Duong, T.; Wan, Y.; Phang, S. P.; Shen, H.; Wu, N.; Barugkin, C.; Fu, X.; et al. Monolithic Perovskite/Silicon-Homojunction Tandem Solar Cell with over 22\% Efficiency. Energy Environ. Sci. 2017, 10, 2472-2479 DOI:10.1039/C7EE02288C.

(34) Mailoa, J. P.; Bailie, C. D.; Johlin, E. C.; Hoke, E. T.; Akey, A. J.; Nguyen, W. H.; McGehee, M. D.; Buonassisi, T. A 2-Terminal Perovskite/Silicon Multijunction Solar Cell Enabled by a Silicon Tunnel Junction. Appl. Phys. Lett. 2015, 106, 121105.

(35) Albrecht, S.; Saliba, M.; Baena, J. P. C.; Lang, F.; Kegelmann, L.; Mews, M.; Steier, L.; Abate, A.; Rappich, J.; Korte, L. Monolithic Perovskite/Silicon-Heterojunction Tandem Solar Cells Processed at Low Temperature. Energy Environ. Sci. 2016, 9, 81-88.

(36) Werner, J.; Barraud, L.; Walter, A.; Bräuninger, M.; Sahli, F.; Sacchetto, D.; Tétreault, N.; Paviet-Salomon, B.; Moon, S.-J.; Allebé, C.; et al. Efficient Near-Infrared-Transparent Perovskite Solar Cells Enabling Direct Comparison of 4-Terminal and Monolithic Perovskite/Silicon Tandem Cells. ACS Energy Lett. 2016, 1, 474-480 DOI:10.1021/acsenergylett.6b00254.

(37) Chen, B.; Bai, Y.; Yu, Z.; Li, T.; Zheng, X.; Dong, Q.; Shen, L.; Boccard, M.; Gruverman, A.; Holman, Z.; et al. Efficient Semitransparent Perovskite Solar Cells for 23.0\%-Efficiency Perovskite/Silicon Four-Terminal Tandem Cells. Adv. Energy Mater. 2016, 6, 1601128 DOI:10.1002/aenm.201601128.

(38) Löper, P.; Moon, S.-J.; Martín de Nicolas, S.; Niesen, B.; Ledinsky, M.; Nicolay, S.; Bailat, J.; Yum, J.-H.; De Wolf, S.; Ballif, C. Organic-inorganic Halide Perovskite/Crystalline Silicon Four-Terminal Tandem Solar Cells. Phys. Chem. Chem. Phys. 2015, 17, 1619-1629 DOI:10.1039/C4CP03788J.

(39) McMeekin, D. P.; Sadoughi, G.; Rehman, W.; Eperon, G. E.; Saliba, M.; Hörantner, M. T.; Haghighirad, A.; Sakai, N.; Korte, L.; Rech, B.; et al. A Mixed-Cation Lead Mixed-Halide Perovskite Absorber for Tandem Solar Cells. Sci. 2016, 351, 151-155 DOI:10.1126/science.aad5845. 
(40) De Wolf, S.; Holovsky, J.; Moon, S.-J.; Löper, P.; Niesen, B.; Ledinsky, M.; Haug, F.-J.; Yum, J.-H.; Ballif, C. Organometallic Halide Perovskites: Sharp Optical Absorption Edge and Its Relation to Photovoltaic Performance. J. Phys. Chem. Lett. 2014, 5, 1035-1039 DOI:10.1021/jz500279b.

(41) Borchert, J.; Milot, R. L.; Patel, J. B.; Davies, C. L.; Wright, A. D.; Martínez Maestro, L.; Snaith, H. J.; Herz, L. M.; Johnston, M. B. Large-Area, Highly Uniform Evaporated Formamidinium Lead Triiodide Thin Films for Solar Cells. ACS Energy Lett. 2017, 2, 2799-2804.

(42) Werner, J.; Weng, C.-H.; Walter, A.; Fesquet, L.; Seif, J. P.; De Wolf, S.; Niesen, B.; Ballif, C. Efficient Monolithic Perovskite/Silicon Tandem Solar Cell with Cell Area $>1 \mathrm{Cm} \mathrm{2.} \mathrm{J.}$ Phys. Chem. Lett. 2016, 7, 161-166 DOI:10.1021/acs.jpclett.5b02686.

(43) Bush, K. A.; Manzoor, S.; Frohna, K.; Yu, Z. J.; Raiford, J. A.; Palmstrom, A. F.; Wang, H.-P.; Prasanna, R.; Bent, S. F.; Holman, Z. C. Minimizing Current and Voltage Losses to Reach 25\% Efficient Monolithic Two-Terminal Perovskite-Silicon Tandem Solar Cells. ACS Energy Lett. 2018, 3, 2173-2180.

(44) ENF. Glass Manufacturers https://www.enfsolar.com/directory/material/glass (accessed Mar 6, 2019).

(45) Miller, D. C.; Annigoni, E.; Ballion, A.; Bokria, J. G.; Bruckman, L. S.; Burns, D. M.; Chen, X.; Feng, J.; French, R. H.; Fowler, S. Degradation in PV Encapsulant Strength of Attachment: An Interlaboratory Study towards a Climate-Specific Test. In 2016 IEEE 43rd Photovoltaic Specialists Conference (PVSC); IEEE, 2016; pp 95-100.

(46) Yousif, E.; Haddad, R. Photodegradation and Photostabilization of Polymers, Especially Polystyrene. Springerplus 2013, 2, 398.

(47) Santbergen, R.; Mishima, R.; Meguro, T.; Hino, M.; Uzu, H.; Blanker, J.; Yamamoto, K.; Zeman, M. Minimizing Optical Losses in Monolithic Perovskite/c-Si Tandem Solar Cells with a Flat Top Cell. Opt. Express 2016, 24, A1288-A1299.

(48) Buehlmann, P.; Bailat, J.; Dominé, D.; Billet, A.; Meillaud, F.; Feltrin, A.; Ballif, C. In Situ Silicon Oxide Based Intermediate Reflector for Thin-Film Silicon Micromorph Solar Cells. Appl. Phys. Lett. 2007, 91, 143505.

(49) Mazzarella, L.; Werth, M.; Jäger, K.; Jošt, M.; Korte, L.; Albrecht, S.; Schlatmann, R.; Stannowski, B. Infrared Photocurrent Management in Monolithic Perovskite/Silicon Heterojunction Tandem Solar Cells by Using a Nanocrystalline Silicon Oxide Interlayer. Opt. Express 2018, 26, A487-A497.

(50) Pascoe, A. R.; Meyer, S.; Huang, W.; Li, W.; Benesperi, I.; Duffy, N. W.; Spiccia, L.; Bach, U.; Cheng, Y. Enhancing the Optoelectronic Performance of Perovskite Solar Cells via a Textured CH 3 NH 3 PbI 3 Morphology. Adv. Funct. Mater. 2016, 26, 1278-1285 DOI:10.1002/adfm.201504190.

(51) Group, I. W. International Technology Roadmap for Photovoltaic (ITRPV) 2017 Results. SEMI, Berlin, Ger. 2017.

(52) Xi, Z.; Yang, D.; Dan, W.; Jun, C.; Li, X.; Que, D. Investigation of Texturization for 
Monocrystalline Silicon Solar Cells with Different Kinds of Alkaline. Renew. Energy 2004, 29, 2101-2107 DOI:10.1016/j.renene.2004.03.003.

(53) Toor, F.; Branz, H. M.; Page, M. R.; Jones, K. M.; Yuan, H.-C. Multi-Scale Surface Texture to Improve Blue Response of Nanoporous Black Silicon Solar Cells. Appl. Phys. Lett. 2011, 99, 103501 DOI:10.1063/1.3636105.

(54) Chow, T. P. Reactive Ion Etching of Silicon in CCl4 and HCl Plasmas. J. Electrochem. Soc. 1987, 134, 1281 DOI:10.1149/1.2100658.

Baker- Finch, S. C.; McIntosh, K. R. Reflection of Normally Incident Light from Silicon Solar Cells with Pyramidal Texture. Prog. Photovoltaics Res. Appl. 2011, 19, 406-416.

Liu, D.; Wang, Q.; Traverse, C. J.; Yang, C.; Young, M.; Kuttipillai, P. S.; Lunt, S. Y.; Hamann, T. W.; Lunt, R. R. Impact of Ultrathin C60 on Perovskite Photovoltaic Devices. ACS Nano 2018, 12, 876-883 DOI:10.1021/acsnano.7b08561.

(57) Sahli, F.; Kamino, B. A.; Werner, J.; Bräuninger, M.; Paviet-Salomon, B.; Barraud, L.; Monnard, R.; Seif, J. P.; Tomasi, A.; Jeangros, Q.; et al. Improved Optics in Monolithic Perovskite/Silicon Tandem Solar Cells with a Nanocrystalline Silicon Recombination Junction. Adv. Energy Mater. 2018, 8, 1701609 DOI:10.1002/aenm.201701609.

(58) Zheng, J.; Lau, C. F. J.; Mehrvarz, H.; Ma, F.-J.; Jiang, Y.; Deng, X.; Soeriyadi, A.; Kim, J.; Zhang, M.; Hu, L.; et al. Large Area Efficient Interface Layer Free Monolithic Perovskite/Homo-Junction-Silicon Tandem Solar Cell with over 20\% Efficiency. Energy Environ. Sci. 2018, 11, 2432-2443 DOI:10.1039/C8EE00689J.

(59) Shen, H.; Omelchenko, S. T.; Jacobs, D. A.; Yalamanchili, S.; Wan, Y.; Yan, D.; Phang, P.; Duong, T.; Wu, Y.; Yin, Y.; et al. In Situ Recombination Junction between P-Si and TiO 2 Enables High-Efficiency Monolithic Perovskite/Si Tandem Cells. Sci. Adv. 2018, 4, eaau9711 DOI:10.1126/sciadv.aau9711.

(60) Cai, D. K.; Neyer, A.; Kuckuk, R.; Heise, H. M. Optical Absorption in Transparent PDMS Materials Applied for Multimode Waveguides Fabrication. Opt. Mater. (Amst). 2008, 30, 1157-1161 DOI:10.1016/j.optmat.2007.05.041.

(61) Morales-Masis, M.; De Wolf, S.; Woods-Robinson, R.; Ager, J. W.; Ballif, C. Transparent Electrodes for Efficient Optoelectronics. Adv. Electron. Mater. 2017, 3, 1600529 DOI:10.1002/aelm.201600529.

(62) Qiu, W.; Merckx, T.; Jaysankar, M.; Masse de la Huerta, C.; Rakocevic, L.; Zhang, W.; Paetzold, U. W.; Gehlhaar, R.; Froyen, L.; Poortmans, J.; et al. Pinhole-Free Perovskite Films for Efficient Solar Modules. Energy Environ. Sci. 2016, 9, 484-489 DOI:10.1039/C5EE03703D.

(63) Rakocevic, L.; Gehlhaar, R.; Merckx, T.; Qiu, W.; Paetzold, U. W.; Fledderus, H.; Poortmans, J. Interconnection Optimization for Highly Efficient Perovskite Modules. IEEE J. Photovoltaics 2017, 7, 404-408 DOI:10.1109/JPHOTOV.2016.2626144.

(64) Duong, T.; Lal, N.; Grant, D.; Jacobs, D.; Zheng, P.; Rahman, S.; Shen, H.; Stocks, M.; Blakers, A.; Weber, K.; et al. Semitransparent Perovskite Solar Cell With Sputtered Front and Rear Electrodes for a Four-Terminal Tandem. IEEE J. Photovoltaics 2016, 6, 679-687 
DOI:10.1109/JPHOTOV.2016.2521479.

(65) Beaucarne, G.; Schubert, G.; Tous, L.; Hoornstra, J. Summary of the 6th Workshop on Metallization and Interconnection for Crystalline Silicon Solar Cells. Energy Procedia 2016, 98, 2-11.

(66) Trube, J.; Metz, A.; Fischer, M.; Hsu, A.; Julsrud, S.; Chang, T.; Tjahjono, B. International Technology Roadmap for Photovoltaic (ITRPV) 2016 Results. Int. Technol. Road Map Photovolt. 2017.

(67) Söderström, T.; Papet, P.; Ufheil, J. Smart Wire Connection Technology. In the 28th European Photovoltaic Solar Energy Conference; 2013; pp 495-499.

(68) Gehlhaar, R.; Merckx, T.; de la Huerta, C. M.; Qiu, W.; Cheyns, D.; Aernouts, T. Perovskite Solar Modules with Minimal Area Loss Interconnections. SPIE Newsroom 2015 DOI:10.1117/2.1201509.006116.

(69) Moon, S.-J.; Yum, J.-H.; Lofgren, L.; Walter, A.; Sansonnens, L.; Benkhaira, M.; Nicolay, S.; Bailat, J.; Ballif, C. Laser-Scribing Patterning for the Production of Organometallic Halide Perovskite Solar Modules. IEEE J. Photovoltaics 2015, 5, 1087-1092 DOI:10.1109/JPHOTOV.2015.2416913.

(70) Mingareev, I.; Berlich, R.; Eichelkraut, T. J.; Herfurth, H.; Heinemann, S.; Richardson, M. C. Diffractive Optical Elements Utilized for Efficiency Enhancement of Photovoltaic Modules. Opt. Express 2011, 19, 11397 DOI:10.1364/OE.19.011397.

(71) Chen, F.; Pathreeker, S.; Kaur, J.; Hosein, I. D. Increasing Light Capture in Silicon Solar Cells with Encapsulants Incorporating Air Prisms to Reduce Metallic Contact Losses. Opt. Express 2016, 24, A1419 DOI:10.1364/OE.24.0A1419.

(72) Saive, R.; Boccard, M.; Saenz, T.; Yalamanchili, S.; Bukowsky, C. R.; Jahelka, P.; Yu, Z. J.; Shi, J.; Holman, Z.; Atwater, H. A. Silicon Heterojunction Solar Cells with Effectively Transparent Front Contacts. Sustain. Energy Fuels 2017, 1, 593-598 DOI:10.1039/C7SE00096K.

(73) Schumann, M. F.; Langenhorst, M.; Smeets, M.; Ding, K.; Paetzold, U. W.; Wegener, M. All-Angle Invisibility Cloaking of Contact Fingers on Solar Cells by Refractive Free-Form Surfaces. Adv. Opt. Mater. 2017, 5, 1700164 DOI:10.1002/adom.201700164.

(74) Langenhorst, M.; Schumann, M. F.; Paetel, S.; Schmager, R.; Lemmer, U.; Richards, B. S.; Wegener, M.; Paetzold, U. W. Freeform Surface Invisibility Cloaking of Interconnection Lines in Thin-Film Photovoltaic Modules. Sol. Energy Mater. Sol. Cells 2018, 182, 294 301 DOI:10.1016/j.solmat.2018.03.034.

(75) Schneider, J.; Turek, M.; Dyrba, M.; Baumann, I.; Koll, B.; Booz, T. Combined Effect of Light Harvesting Strings, Anti-Reflective Coating, Thin Glass, and High Ultraviolet Transmission Encapsulant to Reduce Optical Losses in Solar Modules. Prog. Photovoltaics Res. Appl. 2014, 22, 830-837 DOI:10.1002/pip.2470.

(76) Hörantner, M. T.; Snaith, H. J. Predicting and Optimising the Energy Yield of Perovskiteon-Silicon Tandem Solar Cells under Real World Conditions. Energy Environ. Sci. 2017, 10, 1983-1993 DOI:10.1039/C7EE01232B. 
(77) Langenhorst, M.; Sautter, B.; Schmager, R.; Lehr, J.; Ahlswede, E.; Powalla, M.; Lemmer, U.; Richards, B. S.; Paetzold, U. W. Energy Yield of All Thin-Film Perovskite/CIGS Tandem Solar Modules. Prog. Photovoltaics Res. Appl. 2018, 2, 2754-2761 DOI:10.1002/pip.3091.

(78) Lehr, J.; Langenhorst, M.; Schmager, R.; Kirner, S.; Lemmer, U.; Richards, B. S.; Case, C.; Paetzold, U. W. Energy Yield Modelling of Perovskite/Silicon Two-Terminal Tandem PV Modules with Flat and Textured Interfaces. Sustain. Energy Fuels 2018, 2, 2754-2761 DOI:10.1039/C8SE00465J.

(79) Vos, A. De. Detailed Balance Limit of the Efficiency of Tandem Solar Cells. J. Phys. D. Appl. Phys. 1980, 13, 839-846 DOI:10.1088/0022-3727/13/5/018.

(80) Langenhorst, M.; Sautter, B.; Schmager, R.; Lehr, J.; Ahlswede, E.; Powalla, M.; Lemmer, U.; Richards, B. S.; Paetzold, U. W. Energy Yield of All Thin-Film Perovskite/CIGS Tandem Solar Modules. Prog. Photovoltaics Res. Appl. 2018, accepted DOI:10.1002/pip.3091. 